\title{
Enhancement in electron and ion temperatures due to solar flares as measured by SROSS-C2 satellite
}

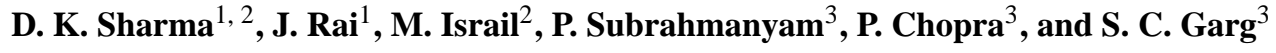 \\ ${ }^{1}$ Department of Physics, Indian Institute of Technology, Roorkee 247 667, India \\ ${ }^{2}$ Department of Earth Sciences, Indian Institute of Technology, Roorkee 247 667, India \\ ${ }^{3}$ Radio \& Atmospheric Science Division, National Physical Laboratory, New Delhi, India
}

Received: 31 January 2003 - Revised: 20 January 2004 - Accepted: 30 March 2004 - Published: 14 June 2004

\begin{abstract}
The observations on the ionospheric electron and ion temperatures $\left(\mathrm{T}_{e}\right.$ and $\left.\mathrm{T}_{i}\right)$ measured by the RPA payload aboard the SROSS-C2 satellite have been used to study the effect of solar flares on ionospheric heating. The data on solar flare has been obtained from the National Geophysical Data Center (NGDC) Boulder, Colorado (USA). It has been found that the electron and ion temperatures have a consistent enhancement during the solar flares on the dayside Earth's ionosphere. The estimated enhancement for the average electron temperature is from 1.3 to 1.9 times whereas for ion temperature it is from 1.2 to 1.4 times to the normal days average temperature. The enhancement of ionospheric temperatures due to solar flares is correlated with the diurnal variation of normal days' ionospheric temperatures. The solar flare does not have any significant effect on the nightside ionosphere. A comparison with the temperature obtained from the IRI95 model also shows a similar enhancement.
\end{abstract}

Key words. Ionosphere (ionospheric disturbances; plasma temperature and density; solar radiation and cosmic ray effects)

\section{Introduction}

Many agencies, such as solar flares, coronal mass injection, seismic activity, volcanoes eruptions, thunderstorms and lightning/sprites, play an important role in changing the ionospheric temperature in the $\mathrm{F}_{2}$-region (Schunk and Sojka, 1996; Sharma et al., 2003a, 2004a, 2004b etc.). The ionospheric temperatures also show variation associated with diurnal, seasonal, latitudinal, longitudinal altitude and in an 11-year solar cycle (Mahajan et al., 1983; Oyama et al., 1996a; Richards, 2001; Sharma et al., 2003b). The change in ionospheric temperatures may affect the radio communication, navigation, exploration of near Earth space, electronic systems in satellites and spacecraft (Kazimirovsky et

Correspondence to: D. K. Sharma

(dksphdes@iitr.ernet.in) al., 2003). Therefore, understanding, monitoring and forecasting the change in the ionospheric temperature due to solar flare is important.

A flare is defined as a sudden, rapid and intense variation in the brightness of the Sun. A flare occurs when magnetic energy that has built up in the solar atmosphere is suddenly released (Carrington, 1860). Radiations are emitted across virtually the entire electromagnetic spectrum, from radio waves at long wavelengths through the optical emissions and X-rays to $\gamma$-rays at short wavelengths. During the solar flares, magnetic energy of $10^{29}$ to $10^{33}$ ergs is released by means of magnetic reconnection (Anastasiadis, 1999). The energy released during solar flare is used in intense localized heating, particle acceleration and in mass flows (Priest, 1992).

The effect of solar flares on total electron content (TEC) has been studied by various workers (Anastasiadis, 1999; Charikov, 2000; Kudryashev and Avakyan, 2000; Avakyan, 2001; Afraimovich et al., 2001) using GPS and satellite data. Afraimovich et al. (2001) have used the GPS network data to study the effect of solar flares of 23 September 1998 and 29 July 1999 . By removing the linear trend of TEC with a time window at about $5 \mathrm{~min}$ they found that the fluctuation of total electron content (TEC) and its time derivative are coherent for all stations on the dayside Earth and no such effect of solar flares was detected on the nightside of the Earth's ionosphere. The effect of solar flares on the ionospheric F-region has also been studied (Mendillo et al., 1974; Mitra, 1974) by a VHF radio beacons experiment on a geo-stationary satellite and the TEC enhancement was noticed. Global observation of the flares of 7 August 1972 using 17 stations in North America, Europe and Africa (Mendillo et al., 1974) revealed that the TEC was increased by $15-30 \%$ during the solar flares. The low latitudes showed a larger increase in the TEC compared with the high latitude. Some events of solar flares have also been studied by Kanellakos et al. (1962) to see the effect on the E- and F-region ionosphere and it has been found that the electron density was enhanced at these heights. Thome and Wagner (1971) theoretically studied the 


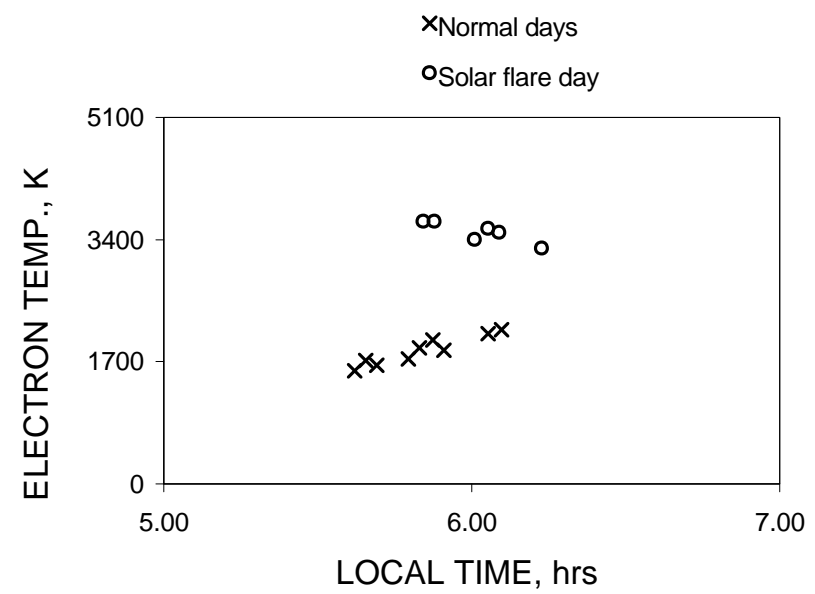

Fig. 1. Variation of electron temperature recorded by the SROSSC2 satellite during solar flares and normal days at Bhopal.

effect of soar flares on electron density and found that the electron density is enhanced in the E- and F-regions of the ionosphere. Thus, various experimental and theoretical studies on the effect of solar flares on TEC have been done in existing literature. However, no study in the author's knowledge is reported for the ionospheric temperature behaviour during solar flares in the $\mathrm{F}_{2}$-region.

The purpose of this paper is to study the effect of solar flares on electron and ion temperatures and its possible correlation with the normal days' ionospheric temperatures. For the present study, the data was obtained by the Retarded Potential Analyzer (RPA) payload aboard Indian SROSS-C2 satellite. The SROSS-C2 satellite was launched by the Indian Space Research Organization (ISRO) on 4 May 1994, to study the ionospheric composition and temperature anomalies. It has yielded valuable data on electron and ion temperatures $\left(\mathrm{T}_{e}\right.$ and $\left.\mathrm{T}_{i}\right)$ over a low-latitude region in the altitude range $425-625 \mathrm{~km}$.

\section{Data collection and analysis}

The satellite data collected during the solar flare events from 1995-1998 using the RPA payload aboard the SROSS-C2 satellite have been analyzed as a response to the solar flare. The data on the solar flare has been obtained from the National Geophysical Data Center (NGDC), Boulder, Colorado, USA. The International Reference Ionosphere (IRI95) model data for the same period were downloaded from the Internet and used for the purpose of comparison. In the subsequent part of the paper the IRI-95 model will be referred to as the IRI model.

The RPA payload aboard the SROSS-C2 satellite consists of two sensors viz., electron and ion sensors and associated electronics (Garg and Das, 1995). The electron and ion RPAs are used for in situ measurements of ionospheric electron and ion temperatures. In addition a spherical Langmuir probe is included and is used as a potential probe for estimating the

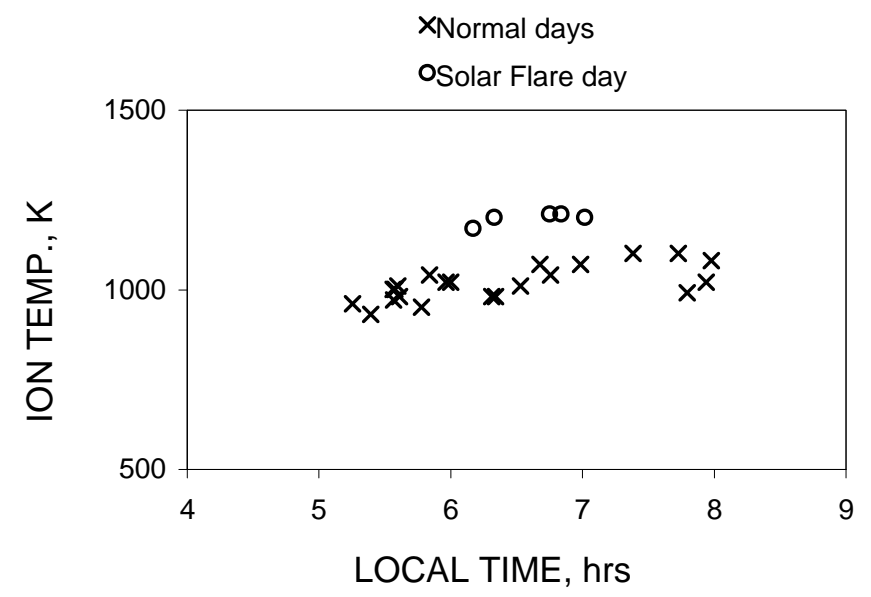

Fig. 2. Variation of ion temperature recorded by the SROSS-C2 satellite during solar flares and normal days at Bhopal.

variation of spacecraft potential during spinning of the satellite. The electron and ion sensors both have planar geometry and consist of multigrided Faraday cups with a collector electrode. The different grids in the sensor are designated as the entrance grid, retarding grid, suppressor grid and screen grid. These grids are made of gold plated tungsten wire mesh having 90 to $95 \%$ optical transparency. The two sensors are mechanically identical but have different grid voltages suitable for collection of electrons and ions, respectively. The charged particles, whose energies are greater than the applied voltage on the retarding grid, pass through various grids and finally reach a collector electrode which causes the sensor current. This current is measured by a linear auto-gain ranging electrometer. The current is translated in terms of electron and ion temperatures.

The IRI is an international project sponsored by the Committee on Space Research (COSPAR) and the International Union on Radio Science (URSI). The IRI describes the median or average value of electron density, ionospheric temperatures (electron, ion and neutrals temperatures) and ion composition as a function of height, location, local time and sunspot number for magnetically quite conditions. It is an empirical model based on the data from the worldwide network of ionosonde stations, incoherent scatter radar and Alouette topside sounders and in situ measurements by several satellites and rockets. The model does not include any effects, such as solar flares, seasonal, diurnal and day-to-day changes, etc.

It is a difficult task to study the ionospheric temperature using the satellites data during solar flares because very rarely do passes of satellites match with the occurrence of solar flares at the meteorological data stations. We have analyzed the data for ten meteorological stations during the period 1995-1998 over India. However, only five events of solar flares have been identified that match with the electron and ion temperatures' data recorded by the satellite. These solar flare events correspond to one event at Bhopal $\left(23.16^{\circ} \mathrm{N}, 77.36^{\circ} \mathrm{E}\right)$, two at Panji $\left(15.30^{\circ} \mathrm{N}, 73.55^{\circ} \mathrm{E}\right)$ and 
two at Pune $\left(18.31^{\circ} \mathrm{N}, 73.55^{\circ} \mathrm{E}\right)$. Data for electron and ion temperatures were analyzed for these locations at the altitude range $425-625 \mathrm{~km}$. Care has been taken to select the satellite data, which is free from diurnal, seasonal, latitudinal, longitudinal and altitude effects by selecting the appropriate data window at a fixed location with $5^{\circ}$ variation in longitude and latitude. A window of $5^{\circ}$ in latitude and longitude for the satellite observations at the meteorological data center has enabled the latitudinal and longitudinal effect to be ineffective. To compute the normal days' temperature for the flare duration, the electron and ion temperatures' data for normal days were selected for the same time interval for a month, which includes about 15 days before the solar flares and about 15 days after the event. Thus, the possibility of diurnal and seasonal effects has been ruled out. The maximum possible data points available for the study duration have been used. The solar flare events selected for the present study are also free from thunderstorms activity, which have been verified using the data on thunderstorm obtained from the India Meteorological Department (IMD), Pune.

All five events studied in the present paper fall in the category of subflare. The area covered by a great flare may be as large as $10^{9} \mathrm{~km}^{2}$ and an area smaller than about $3 \times 10^{8} \mathrm{~km}^{2}$ is known as a subflare (Hanssen and Emslie, 1988). The events studied had nearly the same area, and brilliancy is faint on a three level scale. The intensity of a subflare is approximately $5 \mathrm{sfu}$ (solar flux unit).

\section{Results and discussion}

During 1995-1998, we have identified a total of five solar flare events on the dayside of the Earth, which correspond to the locations at Bhopal, Panji and Pune, over India. These stations were chosen on the basis of maximum passes of the SROSS-C2 satellite. A flare event which appeared on 9 November 1998 from 05:60-06:17 LT (local time) has been analysed the meteorological station at Bhopal $\left(23.16^{\circ} \mathrm{N}, 77.36^{\circ} \mathrm{E}\right)$ in India. Figures 1 and 2 show the electron and ion temperatures during the solar flare and normal days recorded by the SROSS-C2 satellite at Bhopal, respectively. During the solar flare, the average electron temperature was $3446 \mathrm{~K}$, whereas the normal days' temperature was $1795 \mathrm{~K}$ and the temperature estimated by IRI model $2053 \mathrm{~K}$. However, the average ion temperature during this event was $1188 \mathrm{~K}, 1005 \mathrm{~K}$ during normal days and $1021 \mathrm{~K}$ estimated by the IRI model. It may be emphasized here that the flare time nearly matches the local sunrise time. The enhancement in the electron temperature is 1.9 times over the normal days' average electron temperature. However, the ion temperature enhancement during the event was 1.2 times over the normal days' temperature.

The effect of two solar flare events (19 May 1995 from 16:67-17:03 LT and 10 July 1996 from 10:67-11:27 LT) corresponding to the meteorological station at Panji $\left(15.30^{\circ} \mathrm{N}\right.$, $73.55^{\circ} \mathrm{E}$ ) are shown in Figs. $3 \mathrm{a}, \mathrm{b}$ and $4 \mathrm{a}, \mathrm{b}$ for electron and ion temperatures, respectively. During the solar flare of
19 May 1995, the average electron temperature was $2419 \mathrm{~K}$, during normal days it was $1897 \mathrm{~K}$ and estimated by the IRI model at $1726 \mathrm{~K}$. The average ion temperature during the flare event was $1262 \mathrm{~K}$, during normal days it was $1050 \mathrm{~K}$ and $1159 \mathrm{~K}$ estimated by the IRI model. During the solar flare events on 10 July 1996, the average electron temperature was $2005 \mathrm{~K}$; during normal days it was $1382 \mathrm{~K}$, and $1268 \mathrm{~K}$ estimated by the IRI model. The average ion temperature during this event was $1630 \mathrm{~K}$, during normal days it was $1175 \mathrm{~K}$ and $1135 \mathrm{~K}$ estimated by IRI model. It may be mentioned here that these flare events were recorded at 16:6717:03 LT and 10:67-11:27 LT, respectively. The enhancement in the average electron temperature for these events was 1.3 to 1.5 times and for ion temperature it was 1.2 to 1.4 times over the normal days' temperatures.

Two solar flares events corresponding to the meteorological station at Pune $\left(18.31^{\circ} \mathrm{N}, 73.55^{\circ} \mathrm{E}\right)$ were identified on 5 June 1995 from 08:90-10:03 LT and 28 December 1998 from 09:04-09:83 LT. Figures 5a, b and 6a, b show the electron and ion temperatures variation during solar flares and normal days for these events. The average electron temperature during the solar flare on 5 June 1995 was $2367 \mathrm{~K}$, during normal days it was $1613 \mathrm{~K}$ and obtained from the IRI model, 1376,K. During this event, the ion temperature was $1311 \mathrm{~K}, 950 \mathrm{~K}$ during normal days and $1022 \mathrm{~K}$ estimated by the IRI model. During the solar flare on 28 December 1998 the average electron temperature was $2637 \mathrm{~K}$, during normal days it was $1485 \mathrm{~K}$ and obtained from the IRI model, $1534 \mathrm{~K}$. During this event, the average ion temperature was $1630 \mathrm{~K}$, during normal days it was $1233 \mathrm{~K}$ and estimated by IRI model $1351 \mathrm{~K}$. It may be mentioned here that these flare events are recorded at 08:90-10:03 LT and 09:04-09:83 LT, respectively. The enhancement in the average electron temperature for these events was 1.5 to 1.8 times and for the ion temperature it was 1.3 to 1.4 times over the normal days.

All temperature data recorded by the SROSS-C2 satellite are within the error limit of $\pm 50 \mathrm{~K}$ for the temperature range of $500-5000 \mathrm{~K}$. Therefore, the variation in the electron and ion temperatures measured by the SROSS-C2 satellite during the flare time can be interpreted as the ionospheric temperature response to the solar flares. These enhancements have been found on the dayside of the Earth's ionosphere. To see the effect of solar flares on the nightside Earth's ionosphere we have also studied two events at Chennai $\left(13.04^{\circ} \mathrm{N}\right.$, $\left.80.17^{\circ} \mathrm{E}\right)$ and at Panji $\left(15.30^{\circ} \mathrm{N}, 73.55^{\circ} \mathrm{E}\right)$ in India. At Chennai the SROSS-C2 data was available for the solar flare event of 2 February 1997 (19:07-21:30LT) and at Panji on 4 May 1998 (22:20-23:00 LT). The local time for both solar flares over India were night hours. The temperature variation recorded for these events falls within the error limit of the normal temperatures. Hence, it may be concluded that the solar flares do not show any measurable effect on the ionospheric temperature on the nightside Earth's ionosphere. Afraimovich et al. (2001) also concluded that the solar flares don't have any effect on the nightside Earth's ionosphere.

The above analysis shows that there is a consistent enhancement of the ionospheric electron and ion temperatures 


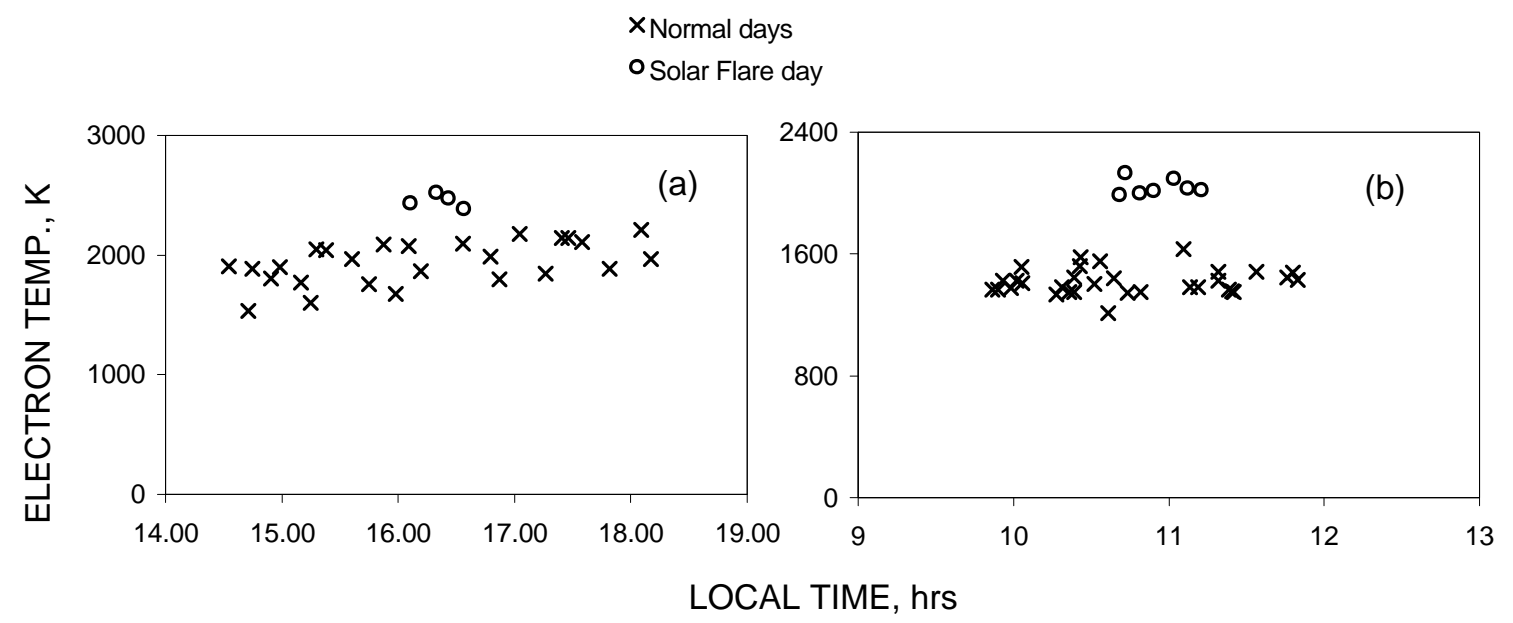

Fig. 3. Variation of electron temperature recorded by the SROSS-C2 satellite during solar flares and normal days at Panji.

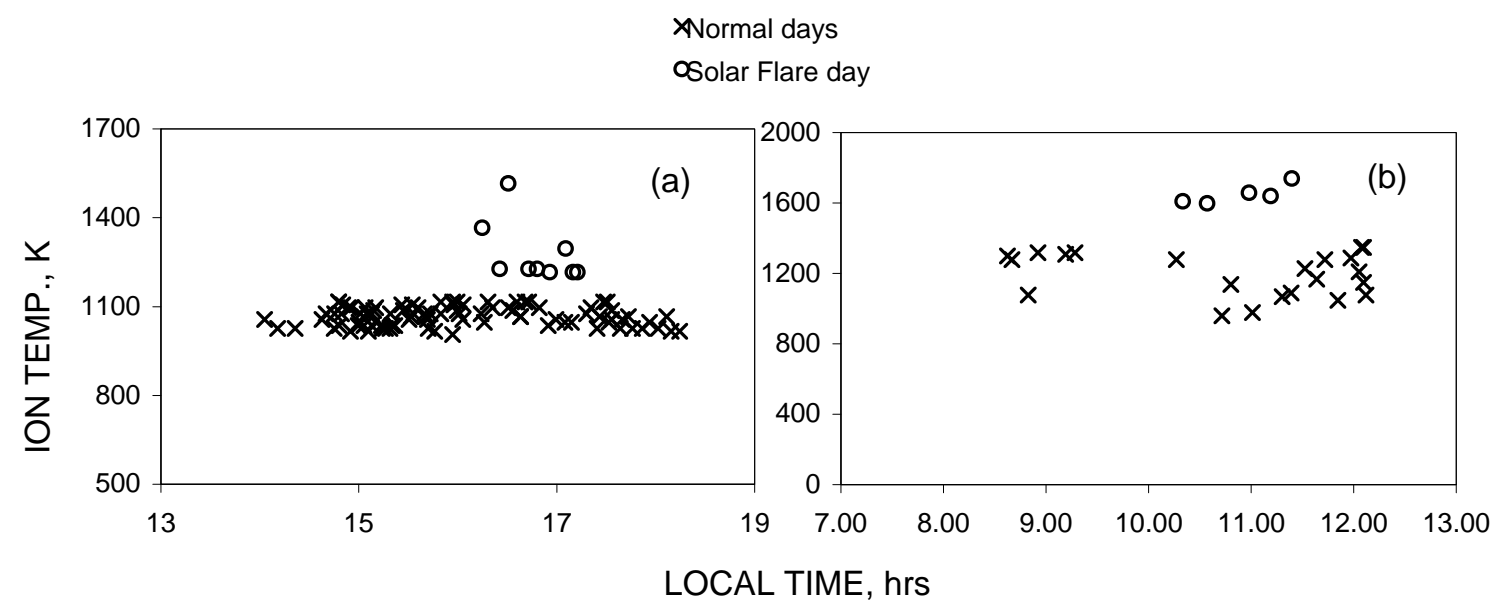

Fig. 4. Variation of ion temperature recorded by the SROSS-C2 satellite during solar flares and normal days at Panji.

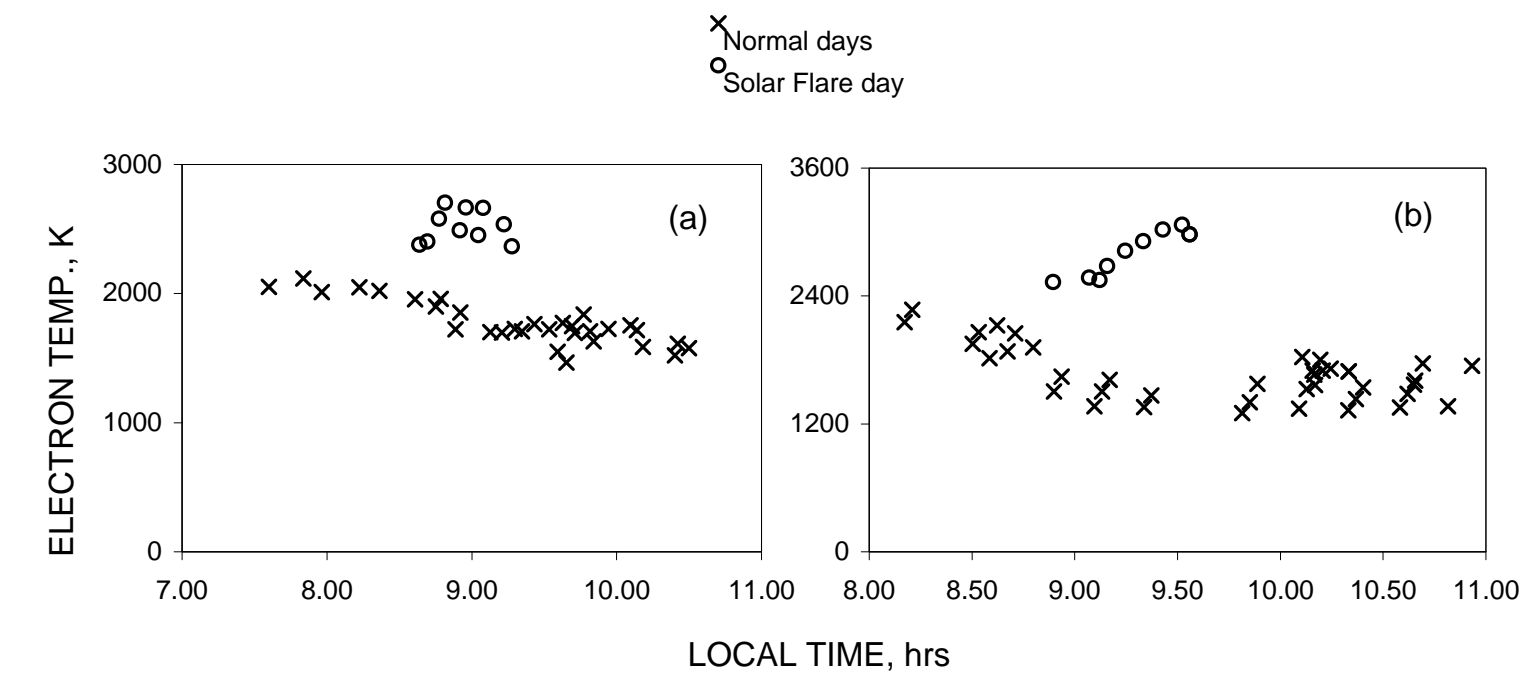

Fig. 5. Variation of electron temperature recorded by the SROSS-C2 satellite during solar flares and normal days at Pune. 
$\times$ Normal days

o Solar Flares day
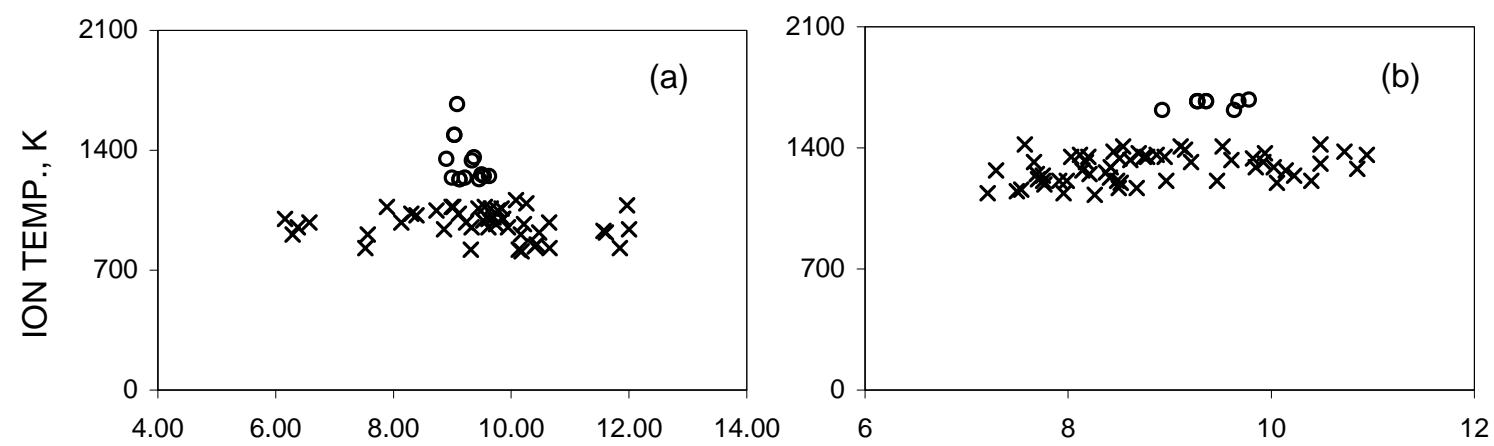

Fig. 6. Variation of ion temperature recorded by the SROSS-C2 satellite during solar flares and normal days at Pune.

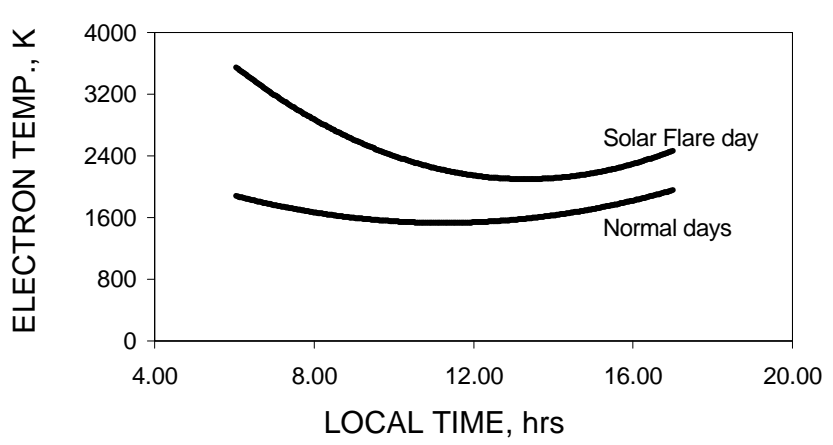

Fig. 7. Diurnal variation of average electron temperature during solar flares and normal days.

recorded during the solar flares. This enhancement for the average electron temperature varies from 1.3 to 1.9 times to the normal days' average temperature. However, for the ion temperature it ranges from 1.2 to 1.4 times to the normal days' average temperature. The data selection and analysis discussed in the previous section shows that the enhancement of ionospheric temperature during the solar flares is the ionospheric temperature, response to the solar flare. It has also been noticed that the solar flare recorded during the sunrise time (05:60-06:17 LT) shows the maximum enhancement in average electron temperature, about 1.9 times over the normal days average temperature, whereas the flares during the sunset time (16:67-17:03 LT) show the least enhancement, about 1.3 times in the average electron temperature over the normal average temperature; no measurable enhancement in electron temperature has been found during the night hours. This suggests that the ionospheric temperature anomalies during the solar flares are directly related to diurnal behaviour of the normal temperatures. Figures 7 and 8 show that the enhancement in electron temperature was maximum during the solar flare at sunrise hours and less enhanced during the events as the day progressed. In the case of the ion temperature (Fig. 8), the ion temperature is less sensitive and the maximum enhancement of the average temperature during the solar flare events is reached at noontime.

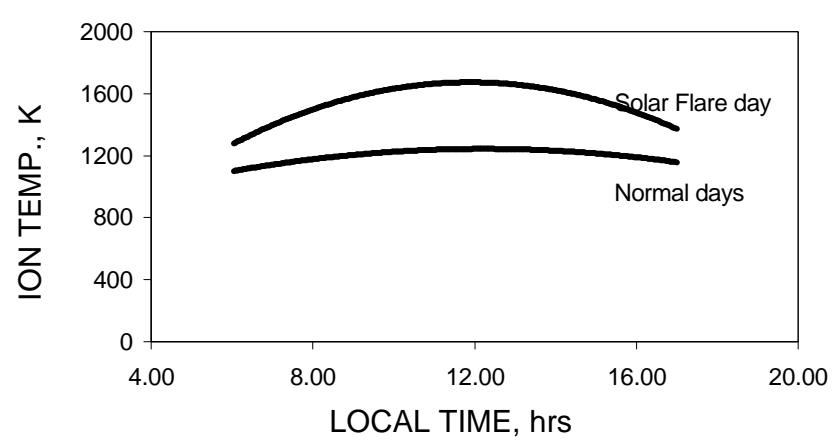

Fig. 8. Diurnal variation of average ion temperature during solar flares and normal days.

Sharma et al. (2003b) have studied the sunrise effect of the ionospheric electron and ion temperatures using the SORSSC2 satellite data over different locations in India and found that the electron temperature is suddenly enhanced during the sunrise hours, while the ion temperature is less sensitive to this effect. Oyama et al. (1996b) have studied the morning overshoot of $\mathrm{T}_{e}$ by the downward plasma drift in the equatorial topside ionosphere and found that the rapid increase in electron temperature in the early morning period is the wellknown $\mathrm{T}_{e}$ phenomenon called "morning overshoot". The present study also indicates that the solar flare response to the electron temperature is maximum during sunrise hours.

The enhancement in ionospheric temperature is mainly due to high energy X-rays and ultraviolet radiation produced during the solar flares (Donnelly, 1976; Charikov, 2000; Kocharov et al., 2000). These high-energy radiation reach the Earth's ionosphere and heat the plasma. All solar flare events selected for the present study had an intensity of about $5 \mathrm{sfu}$. Therefore, in the present study, the variation in the enhancements of electron and ion temperature is correlated with the local time ionospheric temperature variation. 


\section{Conclusions}

The ionospheric temperature anomalies recorded by the SROSS-C2 satellite during 1995-1998 have been analysed in relation to the solar flare events. In all, five subflare events recorded during different local times are matching the SROSS-C2 satellite passes' time. The study reveals that the electron and ion temperatures' show a consistent enhancement during the solar flares. The ionospheric temperatures response to the solar flares is correlated with the local time of the electron and ion temperature behaviour. The enhancement in electron temperature is maximum during the flare at sunrise hours and smaller for the flares recorded as the day progresses. The electron temperature is more sensitive in comparison to the ion temperature. The enhancement in the case of electron temperature is slightly higher than the enhancement in ion temperature. The effect of solar flare on the nightside ionospheric temperatures has not been detected in the altitude range 425 to $625 \mathrm{~km}$. The magnitude of the temperature enhancement depends upon the local time. Since all the flare events studied in the present paper had the same brightness therefore, the study of the temperature enhancement relationship with the magnitude of the brightness of the solar flares is beyond the scope of the present paper.

Acknowledgements. One of the authors (DKS) is thankful to CSIR, New Delhi for providing the financial assistance for this study. Authors are thankful to NGDC, Boulder, Colorado (USA) for provided the data on solar flare.

Topical Editor M. Lester thanks F. Honary for her help in evaluating this paper.

\section{References}

Afraimovich, E. L., Altyntsev, A. T., Kosogorov, E. A., Larina, N. S., and Leonovich, L. A.: Ionospheric effects of the solar flares of September 23, 1998 and July 29, 1999 as deduced from GPS network data, J. Atmos. Solar Terr. Phy., 63, 1841-1849, 2001.

Anastasiadis, A.: Electron acceleration in solar flares by spatially random DC electric fields, Phys. Chem. Earth (C), 24, 269-274, 1999.

Avakyan, S. V.: Some purposes and methods of the satellite measurements of the ignorospheric response on the solar flares, Phys. Chem. Earth (C), 26, 259-263, 2001.

Carrington, R. C.: Description of a singular appearance seen in the sun on September 1, 1859, Monthly Notice of the Royal Astronomical Society, 20, 3-15, 1860.

Charikov, Y. E.: X-ray precursors in solar flares, Phys. Chem. Earth (C), 25, 407, 2000.

Donnelly, R. F.: Empirical models of solar flare X-rays and EUV emission for use in studying their E- and F-region effects, J. Geophys. Res., 81, 4745-4753, 1976.

Garg, S. C. and Das, U. N.: Aeronomy experiments on SROSS-C2, J. Spacecraft Technology, 5, 11-15, 1995.

Hanssen, E. T. and Emslie, A. G.: The physics of solar flares, Cambridge University Press, UK, 7-8, 1988.
Kanellakos, D. P., Chan, K. L., and Villard O. G.: On the altitude at which some solar flare induced ionization is released, J. Geophys. Res., 67, 5-12, 1962.

Kazimirovsky, E., Herraiz, M., and Delamoena, B. A.: Effect on the ionosphere due to phenomena occurring below it, Survey in Geophysics, 24, 139-184, 2003.

Kocharov, G. E., Charikov, Y. E., Lazutkov, V. P., Matveev, G. A., Nitsora, Y. N., Savchenko, M. I., and Skorodumov, D. V.: Soft Xrays in the 00:18 UT solar flare on April 22, 1994, Phys. Chem. Earth (C), 25, 405-406, 2000.

Kudryashev, G. S. and Avakyan, S. V.: Ionization and excitation of the upper atmosphere during solar flares, Phys. Chem. Earth (C), 25, 511-514, 2000.

Mahajan, K. K., Panday, V. K., and Jain, V. C.: Relationship between electron density and electron temperature as a function of solar activity, Adv. Space Res., 2, 247-249, 1983.

Mendillo, M., Klobuchar, J. A., Fritz, R. B., Darosa, A. V., Kersley, L., Yeh, K. C., Flaherty, B. J., Rangaswamy, S., Schmid, J. R., Evans, J. V., Schodel, J. P., Matsoukas, D. A., Koster, J. R., Webster, A. R., and Chin, P.: Behavior of the ionospheric F-region during the great solar flare of August 7, 1972, J. Geophys. Res., 79, 665-672, 1974.

Mitra, A. P.: Ionospheric effect of solar flares, D. Reidel, Norwell, MA, p. 249, 1974.

Oyama, K. I., Watanabe, S., Su, Y., Takahashi, T., and Hirao, K.: Season, local time and longitudinal variations of electron temperature at the height of $\sim 600 \mathrm{~km}$ in the low latitude region, Adv. Space Res., 18, 269-278, 1996a.

Oyama, K. I., Balan, N., Watanabe, S., Takahashi, T., Isoda, F., Bailey, G. J., and Oya, H.: Morning overshoot of $\mathrm{T}_{e}$ enhanced by downward plasma drift in the equatorial topside ionosphere, J. Geomagn. Geoelectr., 48, 959-966, 1996b.

Priest, E. R.: Basic magnetic configuration and energy supply processes for an interacting flux model of eruptive solar flares, edited by Svestka, Z., Jackson, B. and Machado, M., Lecture Notes in Physics, Vol. 399, 15, 1992.

Richards, P. G.: Seasonal and solar cycle variations of the ionosphere peak electron density: Comparison of measurement and models, J. Geophys. Res., 106, 12 803-12 819, 2001.

Schunk, R. W. and Sojka, J. J.: Ionosphere-thermosphere space weather issue, J. Atmos. Solar Terr. Phys., 58, (14), 1527-1574, 1996.

Sharma, D. K., Rai, J., Israil, M., and Garg, S. C.: The effect of lightning on ionospheric temperature determined by SROSS-C2 Satellite, Indian J. Radio Space Phys. 32, 93-97, 2003a.

Sharma, D. K., Rai, J., Israil, M., Priti, S., Subrahmanyam, P., Chopra, P., and Garg, S. C.: Sunrise effect on ionospheric temperature as measured by SROSS-C2 satellite, J. Ind. Geophysical Union, 7, 117-123, 2003b.

Sharma, D. K., Rai, J., Israil, M., Subrahmanyam, P., Chopra, P., and Garg, S. C.: Enhancement in ionospheric temperatures during thunderstorms, J. Atmos. Solar Terr. Phys., 66, 51-56, 2004a.

Sharma, D. K., Rai, J., Israil, M., and Garg, S. C.: Lightning induced heating of the ionosphere, Atmosfera, 17, 31-38, 2004b.

Thome, G. D. and Wagner, L. S.: Electron density enhancements in the E- and F-regions of the ionosphere during solar flares, J. Geophys. Res., 76, 6883-6895, 1971. 